\title{
Fibrous Cellular Structures are Found in a Commercial Fruit Smoothie and Remain Intact during Simulated Digestion
}

Jin Chu, Bridget Dooshima Igbetar and Caroline Orfila*

Nutrition and Public Health Research Group, School of Food Science and Nutrition, University of Leeds, Leeds, UK

\begin{abstract}
The intactness of cell wall structures in foods has important repercussions for nutrient digestion and availability. In this study, we show the presence of intact cell wall structures in a commercial fruit smoothie (blend of banana, mango, orange and apple) and fruit purée (banana, mango), but not in fruit juices (apple or orange). Small clusters of cells were observed in fresh crushed fruit (banana, mango, and apple), the size of the cluster dependent on the type of fruit. When the smoothie was subjected to simulated gastro-intestinal digestion, cell wall structures were found abundantly even after 16 hrs of agitated incubation with digestive enzymes (protease, amylase and amyloglucosidase). Total dietary fibre (TDF) content of the smoothie was measured using the AOAC (991.43) and integrated fibre (IF) analysis methods. TDF-AOAC value was significantly lower (1.61\%) than the TDF-IF (2.22\%), but the ratio of insoluble to soluble dietary fibre (IDF: SDF) was consistently 1:3. Disruption of the cell wall structures in the smoothie by high shear homogenisation led to a $68 \%$ reduction in viscosity, $30 \%$ reduction in TDF content and a $10 \%$ increase in SDF. These experiments suggest that cell wall structures similar to those observed in crushed fruit are preserved during commercial smoothie manufacture and are retained during digestion. Their presence may have implications for fibre quantification and fibre functionality in the gut. We discuss the need to consider fibre structure, as well as content, when evaluating the nutritional properties of fruit and their products.
\end{abstract}

Keywords: Soluble dietary fibre; Insoluble dietary fibre; Cell wall; Fruit smoothie; Simulated digestion; Cellular structures; INFOGEST

Abbreviations: AOAC: Association of Official Analytical Chemists; IF: Integrated Fibre; IDF: Insoluble Dietary Fibre; SDF: Soluble Dietary Fibre; TDF: Total Dietary Fibre

\section{Introduction}

Consumption of fruit and fruit products has been associated with a reduced risk of overall mortality and some non-communicable diseases, leading to intake recommendations of least 3 to 4 portions of fruit a day for the general population $[1,2]$. The protective effect is reduced, but not eliminated, when the fruit is in the juice form, indicating that cellular structure may be important for health beneficial effects. The intactness of cell wall structures has been shown to regulate starch digestion [3,4] and the availability of iron [5] in cooked legumes, and the rate of lipolysis in nuts [6,7]. Intact cellular structures and cell clusters were also observed following chewing of mango and banana fruits [8]. These cellular structures remained visually intact during in vitro colonic fermentation with smaller particles $(<1 \mathrm{~mm})$ fermenting more rapidly that larger ones. In contrast, fermentation of carrot cell clusters showed that particles measuring approximately 150-300 $\mu \mathrm{m}$ were more rapidly fermented than smaller clusters or single cells [9]. These studies suggest that the intactness of cellular structures may affect fruit and vegetable functionality in the gut. Fleshy fruit tissue is made up largely of parenchyma-type cells with thin, elastic cell walls. These cells are inter seeded with rigid vascular fibres. The Total Dietary Fibre (TDF) content of fleshy fruit varies considerably depending on species and ripening stage. Apples, bananas, mangoes and oranges have reported TDF values of $2.21 \%, 1.79 \%, 1.76 \%$ and $2.35 \%$ respectively while orange juice has a reported TFD value of only $0.30 \%$ [10]. Food processing can affect fibre content and properties [11]. For example, the solubility of fibre from a range of legumes was increased following canning [12]. Fruits tend to have higher soluble dietary fibre (SFD) to insoluble dietary fibre (SDF: IDF) ratio of around 1:2, compared to cereals (1:3) and legumes (1:4) [10,12]. While consumption of whole fruits would ensure ingestion of cellular structures, food consumption data indicates that around two thirds of adults do not consume enough fruit (Public Health England, 2016). Fruit beverages such as smoothies have been suggested as convenient and cost effective foods that provide similar nutrient and functionality to whole fruit [13]. Fruit smoothies are blended fruit products, characterised by a viscous consistency compared to fruit juices, though the viscosity varies greatly amongst products. Despite the popularity of smoothies since the 1990's, the fibre properties of smoothies have not been well characterised physically, chemically or biologically. The effect of food processing on cellular structures also needs further investigation.

The analysis of TDF, SDF and IDF is problematic due to the diverse nature of fibre components. The widely used Association of Official Analytical Chemists fibre analysis protocol (AOAC method 991.43) generally includes homogenisation and high temperature amylase digestion steps [14] both of which may affect fibre content and solubility. More recently, protocols using lower incubation temperatures with pancreatic enzymes have been suggested, but not widely adopted $[15,16]$. Recently, a harmonised in vitro simulated digestion protocol was described by the INFOGEST consortium [17]. This method is widely used to investigate protein and lipid digestion, but has not yet been used in the context of fibre analysis. It has been recognised that typical methods of fibre analysis are not likely to reflect physiological function [18]. We postulate that cell wall structure has an effect on fibre measurement.

*Corresponding author: Caroline Orfila, Nutrition and Public Health Research Group, School of Food Science and Nutrition, University of Leeds, Leeds, UK, Tel: +44 113 3432966; Fax: +44 113 3432982; E-mail: c.orfila@leeds.ac.uk

Received December 14, 2016; Accepted January 05, 2017; Published January 12, 2017

Citation: Chu J, Igbetar BD, Orfila C (2017) Fibrous Cellular Structures are Found in a Commercial Fruit Smoothie and Remain Intact during Simulated Digestion. J Nutr Food Sci 7: 576. doi: 10.4172/2155-9600.1000576

Copyright: (c) 2017 Chu J, et al. This is an open-access article distributed unde the terms of the Creative Commons Attribution License, which permits unrestricted use, distribution, and reproduction in any medium, provided the original author and source are credited. 
Citation: Chu J, Igbetar BD, Orfila C (2017) Fibrous Cellular Structures are Found in a Commercial Fruit Smoothie and Remain Intact during Simulated Digestion. J Nutr Food Sci 7: 576. doi: 10.4172/2155-9600.1000576

Page 2 of 5

The aim of this study was to observe whether cell wall structures are present in a commercial fruit smoothie as well as two purées (banana and mango) and two juices (apple and orange), and to compare those structure to those found in crushed fruit (apple, banana, mango). The TDF, SDF and IDF content of the smoothie and juices was measured using the standard AOAC method 991.43 and the more gentle Integrated Fibre (IF) method. We used the INFOGEST protocol to assess the intactness of cell wall structures after digestion. To assess the role of cell wall structure on fibre functionality, the effect of highshear homogenisation on viscosity, fibre content and solubility was evaluated. We discuss the need to consider fibre structure, as well as content, when evaluating the health benefit of fruit and their products.

\section{Materials and Methods}

\section{Food materials}

Fruit smoothie (Magnificent Mango), orange and apple juice, banana and mango purées were all from Innocent Ltd (UK). Ripe fresh fruit (banana, apple, mango and orange) was purchased from a local store. Smoothie samples were homogenised using a Polytron homogeniser (10,000 rpm for $2 \mathrm{~min}, 5 \mathrm{~min}$, and $10 \mathrm{~min}$ ). Fruit samples $(10 \mathrm{~g})$ were crushed using a miniature extrusion Ottawa cell in TA.XT Texture Analyser (Stable Microsystems) using a compression speed of $2 \mathrm{~mm} \mathrm{~s}^{-1}$. Crushed fruit was recovered and used immediately for microscopic observation.

\section{Determination of TDF, SDF and IDF}

Two protocols were used to determine the TDF, SFD and IDF content of the smoothie and the juices. Firstly, the AOAC method 991.43 was used using a total dietary fibre kit (K-TDFR) from Megazyme (Bray, Ireland) with few modifications, namely $5 \mathrm{~g}$ of smoothie, juice or fruit were used instead of $1 \mathrm{~g}$; the fritted glass filters were replaced with three layers of glass filters (GFA, Whatman) placed on ceramic filters. Secondly, the integrated total dietary fibre kit (K-INTDF) from Megazyme (Bray, Ireland) was used, using similar modifications as above. SDF and IDF were separated by ethanol precipitation as per the kits' instructions, except a high speed centrifugation $\left(47,000 \times \mathrm{g}, 4^{\circ} \mathrm{C}\right.$, $60 \mathrm{~min}$ ) step was included to facilitate the separation of the SDF prior to filtration.

\section{Digestion with INFOGEST protocol}

The INFOGEST protocol was applied to the smoothie sample (5 g) according to the protocol [17] except that the oral phase was omitted. At the end of the digestion, the supernatant was observed under the microscope. The undigested residue was collected by filtration as described above. All fibres were dried at $60^{\circ} \mathrm{C}$ and cooled in a desiccator before weighing.

\section{Microscopy}

An aliquot of smoothie, juice or digested fractions was diluted $1: 10$ with $1.5 \mathrm{~N} \mathrm{NaOH}(\mathrm{w} / \mathrm{v})$ containing $0.1 \%(\mathrm{w} / \mathrm{v})$ toluidine blue and $0.25 \%(\mathrm{w} / \mathrm{v})$ calcofluor white (Fluorescent Brightener 28, both stains from Sigma-Aldrich, UK) and incubated for $10 \mathrm{~min}$. Suspensions were directly placed onto poly lysine covered glass slides, covered with a glass cover slip and observed under an inverted microscope equipped with UV fluorescence (Olympus-BH2). Crushed fruit were suspended in water and stained as described.

\section{Viscosity determination}

The viscosity of the smoothie and juices were determined using a Bohlin C-VOR Shear Rheometer with an axial geometry, at minimum and maximum shear rates of 0.1 and $200 \mathrm{l} \mathrm{s}^{-1}$.

\section{Results}

\section{Presence of intact cell wall structures in crushed fruit, purées and smoothie but not in juices}

Fruit was crushed using an extrusion probe designed to simulate the chewing process in the mouth. Crushed fruit contained clusters of intact cells with smaller clusters observed in mango ( $<10$ cells/cluster) followed by banana ( $<15-20$ cells/cluster) and apple ( $>50$ cells/cluster). Crushed apple had broken cells at the periphery of the cluster indicating cell breakage and stronger cell adhesion in apple compared to the other fruits. Starch granules could be clearly observed within banana cells, but not in mango or apple cells Calcofluor white staining showed that the structures contained cellulosic material (Figures 1A-1F). Cellular structures similar to those present in fruits were observed in the banana purée (Figures $2 \mathrm{~A}$ and $2 \mathrm{~B}$ ). In the mango purée, stringy fibre like structures were observed which looked like disrupted cells (Figures $2 \mathrm{C}$ and 2D). In juices, only scattered stringy ribbons, presumed to be of vascular origin, and were observed (Figures $2 \mathrm{E}-2 \mathrm{H}$ ).

Intact cellular structures were also found suspended in the smoothie with a calculated density of 3300 cells per $\mathrm{mL}$ (Figure 3A and 3B). The cell structures were generally single cells of elongated oval shapes with a range of sizes from 50 to around $400 \mu \mathrm{m}$ in diameter. Toluidine blue staining revealed cytoplasmic content within the cells, but no obvious starch granules (Figure $3 \mathrm{~A}$ ). The results suggest that commercial smoothie processing preserves the cellular structures of fruits.

High-sheer homogenisation for $10 \mathrm{~min}$ of the smoothie led to a marked reduction in calcofluor staining and a disruption of the cellular structures (Figures 3C and 3D). The observed ribbon-like structures were similar to those found in mango purée (Figures 2C and 2D). Following simulated digestion of smoothie, cellular structures were abundantly present, even after 16 hrs of gastro-intestinal digestion (Figures 3E and 3F). These results support previous observations for chewed fruit [8] and suggest that fruit parenchyma cells withstand human digestive processes. It is likely, as was observed by Low et al., that the smoothie structures would be fermented by colonic bacteria.

\section{Determination of TDF, SFD and IDF content of smoothie and juices}

The TDF content of commercial smoothie, as well as two fruit juices, were determined using two fibre protocols (Table 1). The smoothie AOAC-TDF content was around 30\% lower level than when the IF method was used $(\mathrm{p}<0.05)$. The AOAC 991.43 method includes a $30 \mathrm{~min}$ high temperature heating step $\left(100^{\circ} \mathrm{C}\right)$ which may destroy the cellular structure. Heating of potato tubers using different processing methods led to separation of cells, but maintenance of cell wall integrity [19]. The IF method which uses pancreatic amylase at $37^{\circ} \mathrm{C}$ is more representative of physiological conditions and likely to preserve fibre cellular structures (as supported by observation of intact cellular structure following the INFOGEST protocol shown in Figures $3 \mathrm{E}$ and $3 \mathrm{~F}$.

Homogenisation significantly decreased the TDF content of the smoothie by about $10 \%(\mathrm{p}<0.05)$ using both methods. As seen in Figures $3 \mathrm{C}$ and $3 \mathrm{D}$, homogenisation destroys the cellular structures and also results in some fibre loss. However, it appears that homogenisation affects fibre content less than heating. There was moderate positive association between viscosity and fibre content $\left(R^{2}=0.7136\right)$.

The proportion of soluble to insoluble fibre was calculated (Table 1). In smoothie, SDF and IDF made up 65 and $35 \%$ of the total fibre 
Citation: Chu J, Igbetar BD, Orfila C (2017) Fibrous Cellular Structures are Found in a Commercial Fruit Smoothie and Remain Intact during Simulated Digestion. J Nutr Food Sci 7: 576. doi: 10.4172/2155-9600.1000576
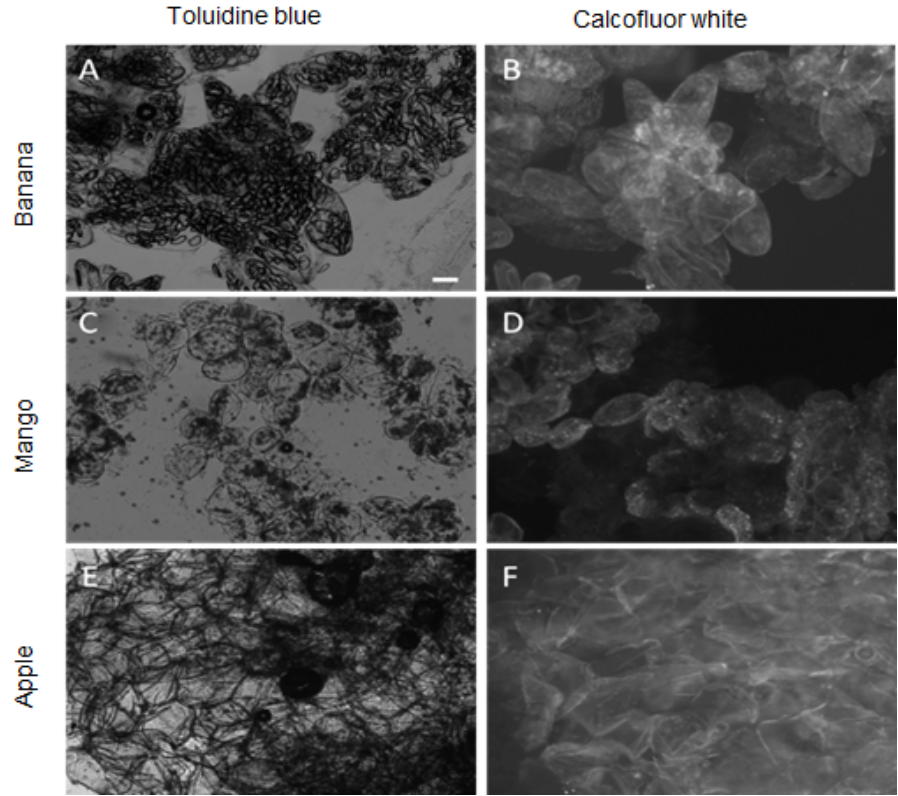

Figure 1: Light and UV microscopy images of crushed fruits. Cellular contents were stained with toluidine blue $(A, C, E)$ revealing abundant starch granules in banana (A) and to a lesser extent in mango (C), but not in apple (A). Cell walls were stained with calcofluor white (A, D, F) showing cellular clusters in all fruits. Scale bar=10 $\mu \mathrm{m}$.

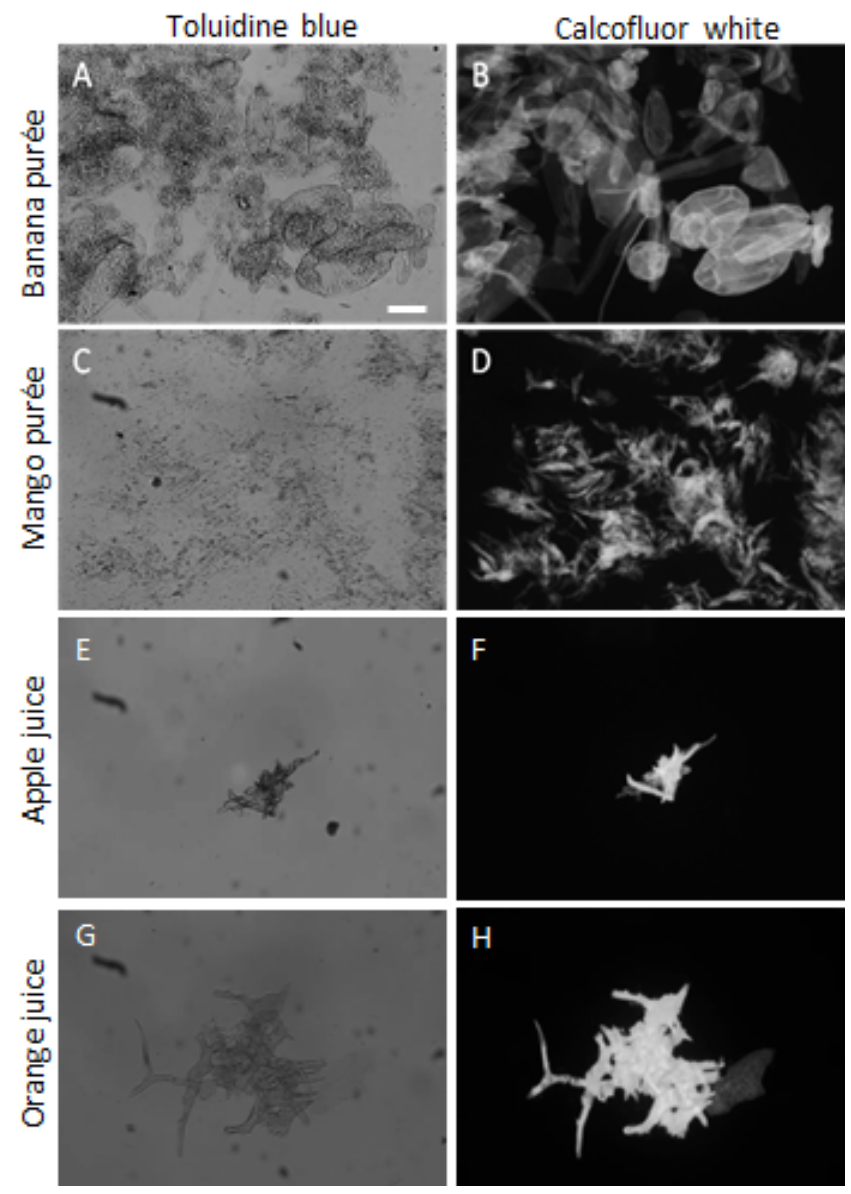

Figure 2: Light and UV microscopy images of puréed or juiced fruits. Cellular contents were stained with toluidine blue (A, C, E, and G), there were no apparent starch granules stained. Cell walls were stained with calcofluor white $(B, D, F$, and $H)$ showing cellular structures in the banana puree (B) but not in mango purée (D), apple $(\mathrm{F})$ or orange juice $(\mathrm{H})$. Scale bar $=10 \mu \mathrm{m}$. 
Citation: Chu J, Igbetar BD, Orfila C (2017) Fibrous Cellular Structures are Found in a Commercial Fruit Smoothie and Remain Intact during Simulated Digestion. J Nutr Food Sci 7: 576. doi: 10.4172/2155-9600.1000576
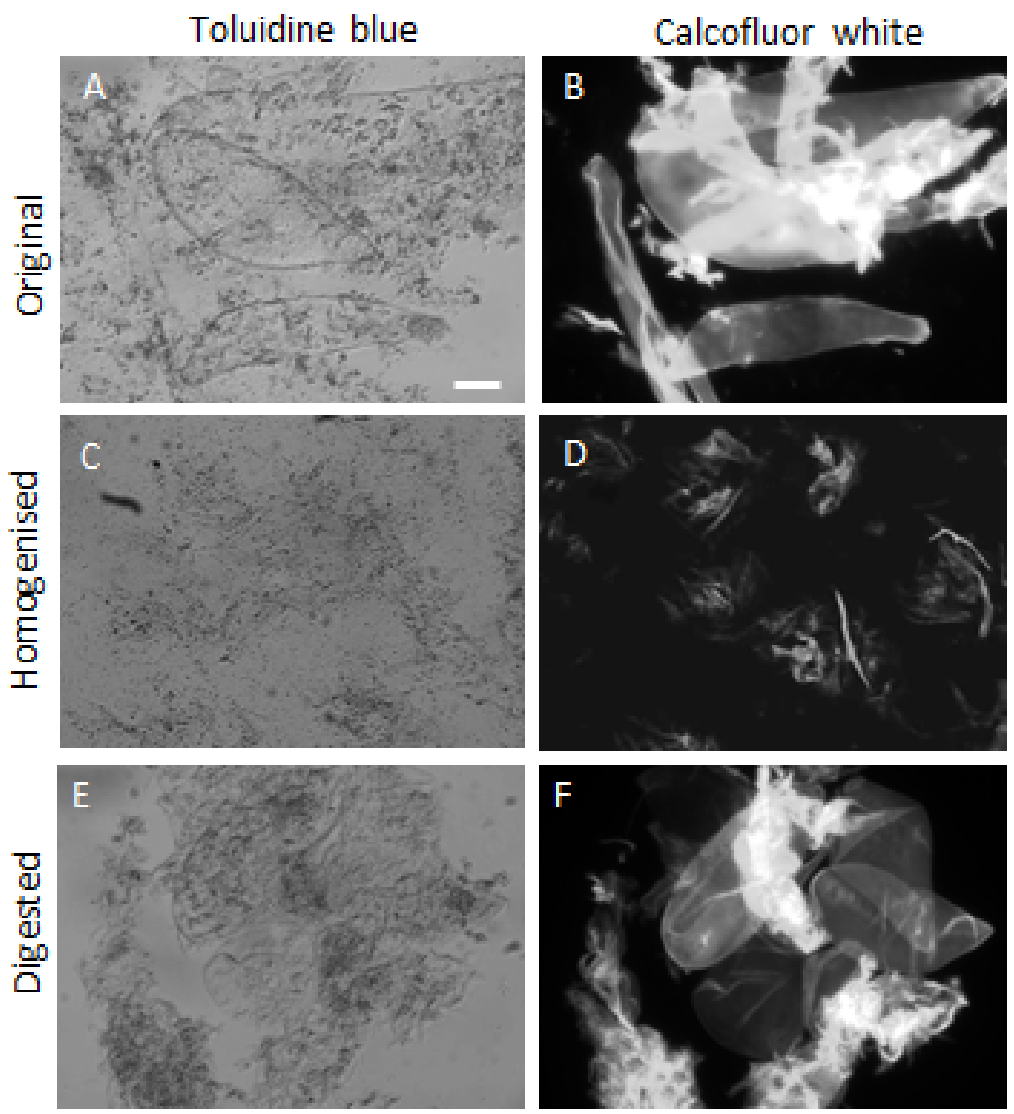

Figure 3: Light and UV microscopy images of commercial smoothie sample. Original smoothie, homogenised and digested smoothie were stained with toluidine blue $(A, C, E)$ to reveal cellular contents. No starch granules were identified. Cell walls were stained with calcofluor white (B, D, and F). Intact cellular structures were observed in original and digested smoothie, but not in the homogenised sample. Scale bar=10 $\mu \mathrm{m}$.

\begin{tabular}{|c|c|c|c|c|c|}
\hline & \multicolumn{2}{|c|}{ TDF } & SDF & IDF & IDF:SDF \\
\cline { 2 - 6 } & AOAC & Integrated & AOAC & AOAC & AOAC \\
\hline Smoothie (Original) & $1.6(0.1)^{\mathrm{a}}$ & $2.2(0.3)^{\mathrm{d}}$ & $1.2(0.1)^{\mathrm{b}}$ & $0.4(0.1)^{\mathrm{d}}$ & $1: 3$ \\
\hline $\begin{array}{c}\text { Smoothie } \\
\text { (Homogenised) }\end{array}$ & $1.2(0.1)^{\mathrm{b}}$ & $1.6(0.3)^{\mathrm{a}}$ & $1.0(0.1)^{\mathrm{c}}$ & $0.2(0.1)^{\mathrm{e}}$ & 1.5 \\
\hline Orange Juice & $0.9(0.1)^{\mathrm{c}}$ & $1.2(0.2)^{\mathrm{b}}$ & $0.8(0.1)^{\mathrm{c}}$ & $0.2(0.1)^{\mathrm{e}}$ & $1: 4$ \\
\hline Apple Juice & 0 & 0 & ND & ND & ND \\
\hline
\end{tabular}

Table 1: Total dietary fibre (TDF) analysed using two different analytical methods, the AOAC (991.43) and integrated protocol. Soluble dietary fibre (SDF) and insoluble dietary fibre (IDF) measured with the AOAC method and ratio of IDF:SDF. Values show mean of at least three replicate determinations and standard deviation of the mean in parentheses. Different letters show significant different values according to one factor ANOVA (95\% confidence). NA: Not applicable; ND: Not determined.

content respectively (ratio SDF: IDF of 3:1). The proportion of SDF is higher than what is reported for whole fruit (SDF:IDF of 1:2) [10]. SDF increased significantly with homogenisation time to account up to $75 \%$ of total fibre after 10 min of homogenisation. In summary, cell wall structures were observed in all crushed fruits, some purées and the smoothie sample. Structures are preserved during simulated digestion. Homogenisation disrupts the cellular structure, reduces fibre content and viscosity.

\section{Discussion}

The importance of food structure for health functionality is increasingly being recognised [20]. Cell walls are natural structures that occur in plant foods that offer a natural barrier to molecular exchange and enzymatic digestion of cellular contents [18]. Most studies on cellular structures have focused on legumes and nuts which have relatively thick and rigid cell walls [21]. These act as physical barriers to digestion and nutrient release. In fruits, cell walls are relatively thinner, but appear remarkably resilient. Potato tubers have thin parenchymatype cell walls which appear to resist heat processing, but do not appear to restrict digestion of starch within the cells [19]. Fruit cellular structures have been observed after chewing of banana and mango fruits [8] and these structures were largely preserved during in vitro digestion. The preservation of the cellular structures in processed fruit products has not been previously shown. In the present study, we show that a commercial sample of smoothie has a high concentration of apparently intact fruit cells which are also preserved during digestion. This indicates that smoothie processing would offer similar benefits to whole fruit to consumers. The health implications of these structures is not yet clear but they may contribute to the physiological benefits of plant foods, independent of total fibre content. These effects may partly explain why fruit juices offer lower disease protection compared to whole fruits, even though the chemical composition is very similar. Most dietary surveys do not have enough categorisation of fruit products and this has been suggested as an issue in not only measuring what people consume but also in formulating clear nutritional advice [22]. The physical properties of fibre are important for its function. Yet, the analytical techniques used to quantify fibre content for composition tables and epidemiological studies are methods that destroy these 
Citation: Chu J, Igbetar BD, Orfila C (2017) Fibrous Cellular Structures are Found in a Commercial Fruit Smoothie and Remain Intact during Simulated Digestion. J Nutr Food Sci 7: 576. doi: 10.4172/2155-9600.1000576

Page 5 of 5

physical characteristics and may not give a physiological indication of fibre functionality. We suggest that epidemiological and interventional studies consider fibre structure, as well as content and solubility, when evaluating the nutritional properties of fruit and their products.

\section{Acknowledgements}

This work was supported by Innocent limited grant number 107319. We thank Sara Viney and Thomas Pons for technical assistance.

\section{References}

1. Oyebode O, Gordon-Dseagu V, Walker A, Mindell JS (2014) Fruit and vegetable consumption and all-cause, cancer and CVD mortality: analysis of Health Survey for England data. J Epidemiol Community Health 68: 856-862.

2. Wang X, Ouyang YY, Liu J, Zhu MM, Zhao G, et al. (2014) Fruit and vegetable consumption and mortality from all causes, cardiovascular disease, and cancer: systematic review and dose-response meta-analysis of prospective cohort studies. BMJ 349: 14.

3. Dhital S, Bhattarai RR, Gorham J, Gidley MJ (2016) Intactness of cell wall structure controls the in vitro digestion of starch in legumes. Food Funct 7 : 1367-1379.

4. Brummer Y, Kaviani M, Tosh SM (2015) Structural and functional characteristics of dietary fibre in beans, lentils, peas and chickpeas. Food Res Int 67: 117-125.

5. Glahn RP, Tako E, Cichy K, Wiesinger J (2016) The cotyledon cell wall and intracellular matrix are factors that limit iron bioavailability of the common bean (Phaseolus vulgaris). Food Funct 7: 3193-3200.

6. Kong FB, Singh RP (2009) Digestion of Raw and Roasted Almonds in Simulated Gastric Environment. Food Biophys 4: 365-377.

7. Ellis PR, Kendall CWC, Ren YL, Parker C, Pacy JF, et al. (2004) Role of cell walls in the bioaccessibility of lipids in almond seeds. Am J Clin Nutr 80: 604613.

8. Low DY, Williams BA, D'Arcy BR, Flanagan BM, Gidley MJ (2015) In vitro fermentation of chewed mango and banana: particle size, starch and vascular fibre effects. Food Funct 6: 2464-2474.

9. Day L, Gomez J, Oiseth SK, Gidley MJ, Williams BA (2012) Faster Fermentation of Cooked Carrot Cell Clusters Compared to Cell Wall Fragments in vitro by Porcine Feces. J Agric Food Chem 60: 3282-3290.

10. Li BW, Andrews KW, Pehrsson PR (2002) Individual sugars, soluble, and insoluble dietary fiber contents of 70 high consumption foods. J Food Compost Anal 15: 715-723.
11. Tejada-Ortigoza V, Garcia-Amezquita LE, Serna-Saldivar SO, Welti-Chanes J (2016) Advances in the Functional Characterization and Extraction Processes of Dietary Fiber. Food Eng Rev 8: 251-271.

12. Aldwairji MA, Chu J, Burley VJ, Orfila C (2014) Analysis of dietary fibre of boiled and canned legumes commonly consumed in the United Kingdom. J Food Compost Anal 36: 111-116.

13. Rehm CD, Drewnowski A (2016) Dietary and economic effects of eliminating shortfall in fruit intake on nutrient intakes and diet cost. BMC Pediatr 16: 83.

14. Lee SC, Prosky L, Devries JW (1992) Determination of total, soluble, and insoluble dietary fiber in foods-enzymatic gravimetric method, Mes-Tris buffercollaborative study. J AOAC Int 75: 395-416.

15. McCleary BV (2007) An integrated procedure for the measurement of total dietary fibre (including resistant starch), non-digestible oligosaccharides and available carbohydrates. Anal Bioanal Chem 389: 291-308.

16. McCleary BV, Sloane N, Draga A (2015) Determination of total dietary fibre and available carbohydrates: A rapid integrated procedure that simulates in vivo digestion. Starch-Starke 67: 860-883.

17. Minekus M, Alminger M, Alvito P, Ballance S, Bohn T, et al. (2014) A standardised static in vitro digestion method suitable for food-an international consensus. Food Funct 5: 1113-1124.

18. Grundy MML, Edwards CH, Mackie AR, Gidley MJ, Butterworth PJ, et al (2016) Re-evaluation of the mechanisms of dietary fibre and implications for macronutrient bio accessibility, digestion and postprandial metabolism. $\mathrm{Br} \mathrm{J}$ Nutr 116: 816-833.

19. Tian J, Chen S, Wu C, Chen J, Du X, et al. (2016) Effects of preparation methods on potato microstructure and digestibility: An in vitro study. Food Chem 211: 564569.

20. Singh J, Berg T, Hardacre A, Boland MJ (2014) Cotyledon Cell Structure and In vitro Starch Digestion in Navy Beans. In: Boland M, Golding M, Singh H (eds.) Food Structures, digestion and health. Elsevier Academic Press, San Diego, USA

21. Berg T, Singh J, Hardacre A, Boland MJ (2012) The role of cotyledon cell structure during in vitro digestion of starch in navy beans. Carbohyd Polym 87: 1678-1688.

22. Ridoutt B, Baird D, Bastiaans K, Hendrie G, Riley M, et al. (2016) Changes in Food Intake in Australia: Comparing the 1995 and 2011 National Nutrition Survey Results Disaggregated into Basic Foods.
Citation: Chu J, Igbetar BD, Orfila C (2017) Fibrous Cellular Structures are Found in a Commercial Fruit Smoothie and Remain Intact during Simulated Digestion. J Nutr Food Sci 7: 576. doi: 10.4172/2155-9600.1000576
OMICS International: Open Access Publication Benefits \& Features

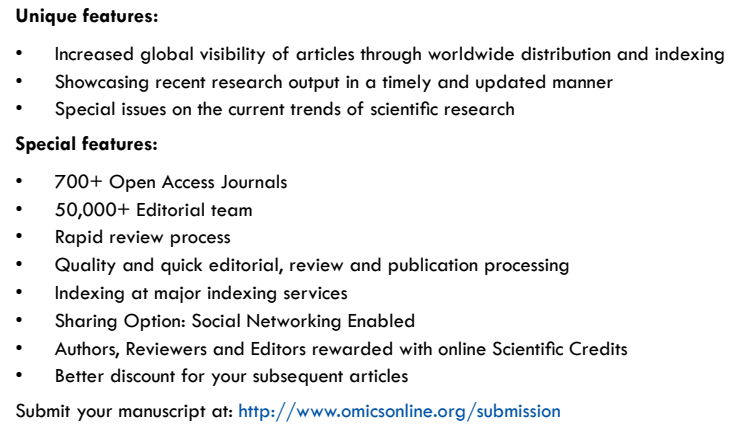

